\title{
Leitura e produção de texto no ensino
}

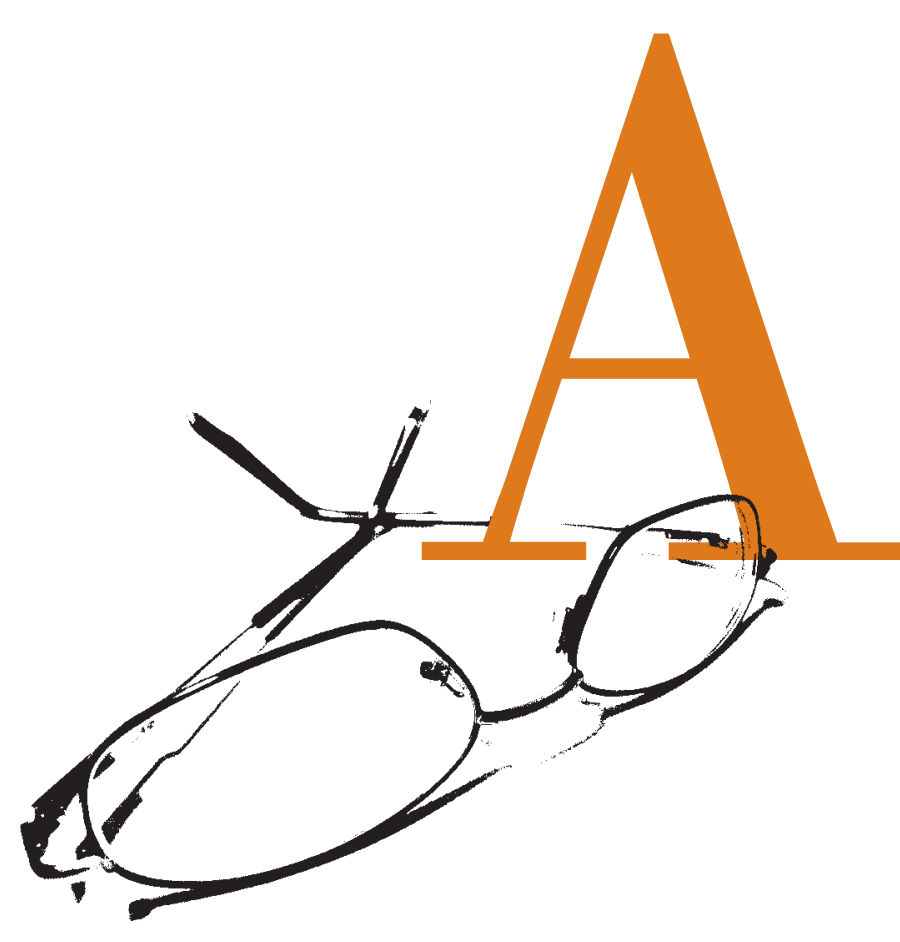

prendemos a ler e a produzir textos orais e escritos em diferentes espaços e grupos sociais. Há uma aprendizagem de fala, leitura e escrita que se dá por meio da escuta, do gesto, da observação, da imitação, de informações colhidas em diferentes espaços e situações.

A escola, no entanto, tem como função desenvolver um trabalho intencional, planejado e sistemático para ampliar essas aprendizagens e possibilitar, às novas gerações, o acesso a discursos mais complexos, como aqueles produzidos pela Ciência, pela esfera política e pela mídia.

A Lei de Diretrizes e Bases da Educação (Lei n. 9394, 1996) estabelece, como um de seus objetivos,

(...) o desenvolvimento da capacidade de aprender, tendo como meios básicos o pleno domínio da leitura, da escrita e do cálculo (seção III, art. 32ํㅡ, I).

A escola é um importante espaço de letramento. E letramento, segundo Magda Soares (1998),

(...) é o que as pessoas fazem com as habilidades de leitura e escrita, em um contexto específico, e como essas habilidades se relacionam com as necessidades, valores e práticas sociais.

Por exemplo: comprar e ler o jornal para se informar sobre o que acontece no mundo, escrever uma carta para a coluna do leitor, posicionando-se sobre determinada matéria, sentir prazer ao ler um romance, preencher um formulário ao solicitar um emprego etc. É também Magda Soares que nos chama a atenção para

* Zoraide Faustinoni é autora de livros didáticos e pesquisadora do CENPEC da área de Gestão e Sistemas de Ensino. 
o fato de que, muitas vezes, os sujeitos são capazes de comportamentos escolares letrados, mas são incapazes de lidar com os usos cotidianos da escrita em contextos não escolares.

Outros autores (Costa, 2000; Tfouni, 2002) entendem que o letramento inclui também a produção de textos orais (por exemplo: a capacidade de fazer narrativas e relatos orais, de se sair bem numa entrevista, de participar de uma assembléia do sindicato ou do condomínio do prédio, de ministrar uma aula, de fazer uma exposição oral em um congresso ou seminário), uma vez que, nas sociedades letradas, há uma intersecção entre oralidade e escrita.

Segundo Bakhtin $(1929 ; 1990)$, os textos orais ou escritos que produzimos são formas de expressão que se originam nas necessidades criadas em diferentes esferas da comunicação humana. Essas formas de dizer não são inventadas a cada vez que nos comunicamos, elas estão à nossa disposição, circulam nos diferentes meios sociais, tenhamos ou não consciência delas.

Os gêneros são formas relativamente estáveis de enunciados, disponíveis na cultura, e podem ser definidos por três aspectos básicos coexistentes:

- seus temas: o que é dizível ou pode se tornar dizível, por meio do gênero;

- sua construção composicional: forma particular dos textos pertencentes ao gênero;

- seu estilo: seleção, feita pelo autor, de recursos da língua - do vocabulário, de gramática - tendo em vista o gênero.

Para Schenewly (2004), o gênero é uma ferramenta, um instrumento com o qual é possível exercer uma ação lingüística sobre a realidade. Segundo esse autor, o uso de uma ferramenta resulta em dois efeitos diferentes de aprendizagem: por um lado, amplia as capacidades individuais do usuário; por outro, aumenta seu conhecimento a respeito do objeto sobre o qual a ferramenta é utilizada.

\section{Linguagem e participação social}

No plano da linguagem, a aprendizagem dos diversos gêneros discursivos que socialmente circulam entre nós não somente amplia a competência lingüística e discursiva dos alunos, como também lhes aponta inúmeras formas de participação social que eles, usando a linguagem, podem ter como cidadãos.
Ao aprender como são

feitas e qual a finalidade

das cartas argumentativas

de solicitação e de reclamação, o aluno não

apenas se apropria de informações sobre o seu

conteúdo, a sua estrutura,

o seu estilo e sobre a

linguagem mais adequada

a esse gênero, como

também toma consciência

de que os cidadãos têm

o direito de reclamare

solicitar providências das

autoridades competentes.

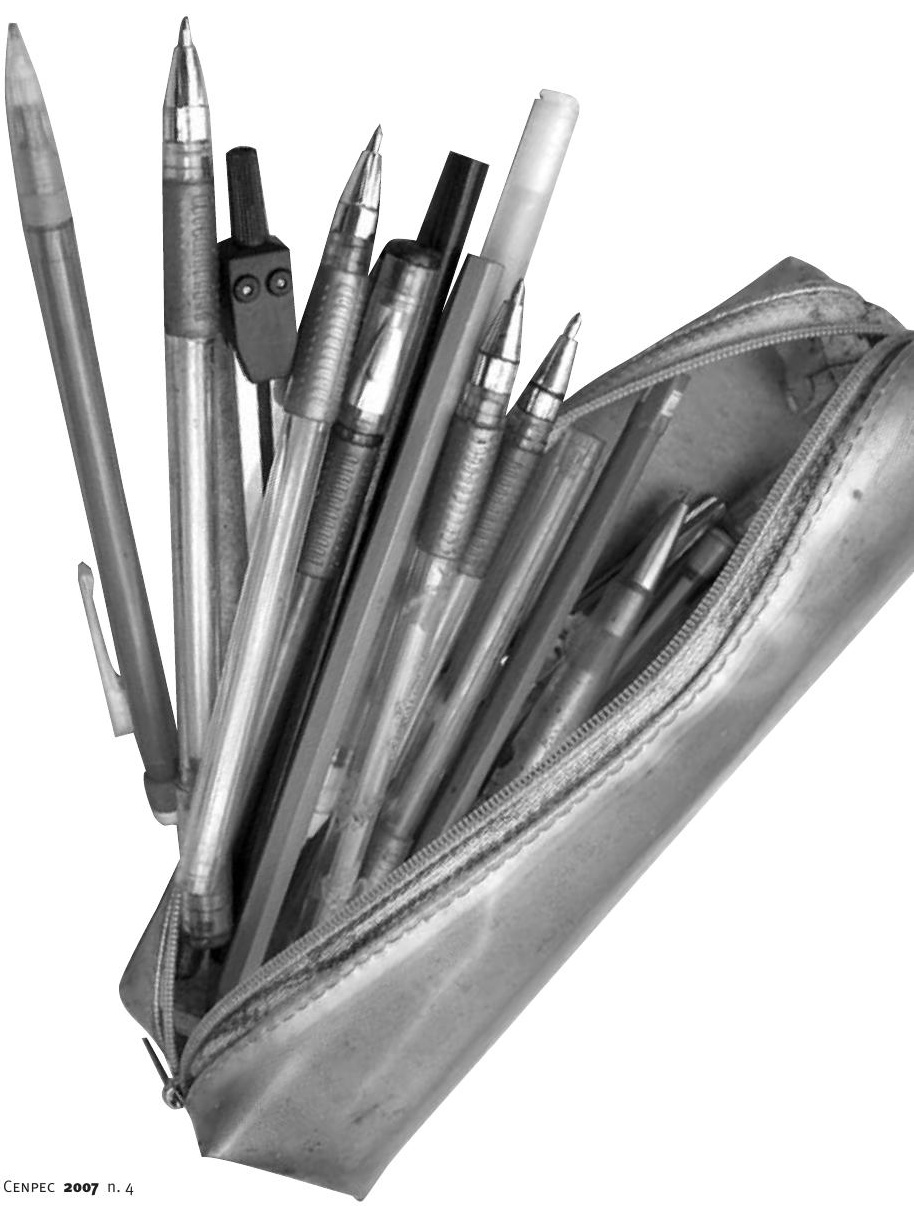


Por exemplo, ao aprender a ler o jornal - a reconhecer as intenções de quem escreve, os recursos utilizados para atingir determinado leitor, a comparar a forma como diferentes jornais publicam uma mesma notícia, quais assuntos são objeto de destaque etc. - os alunos começam a penetrar nessa esfera de comunicação tão importante para a formação de opinião.

Ao aprender como são feitas e qual a finalidade das cartas argumentativas de solicitação e de reclamação, o aluno não apenas se apropria de informações sobre o seu conteúdo, a sua estrutura, o seu estilo e sobre a linguagem mais adequada a esse gênero, como também toma consciência de que os cidadãos têm o direito de reclamar e solicitar providências das autoridades competentes.

Por meio de estudo de gêneros, tais como bulas de remédio e rótulos de embalagens, aprendem sobre os cuidados com a saúde e os direitos do consumidor. Ou ainda, no campo criativo, percebem que podem apreciar e criar textos para a fruição estética e reflexão crítica, como o poema, as letras de canções e as narrativas de ficção em geral.

É imprescindível, portanto, que a escola desenvolva capacidades que possibilitem aos cidadãos a meIhor participação possível em situações de fala e escuta, de leitura e produção de textos com diferentes finalidades.

\section{0 que os exames de leitura indicam}

\section{Exames de leitura, como o Sistema de Avaliação da} Educação Básica - SAEB, e o Programa Internacional de Avaliação de Alunos - PISA e a pesquisa realizada pelo Instituto Montenegro com o objetivo de construir um Indicador de Alfabetismo Funcional - INAF indicam aspectos que poderiam ser mais bem trabalhados pela escola. Sabemos que essas avaliações têm limites. A esse respeito, é importante conhecer as reflexões feitas por diferentes autores, como Ribeiro (2003) e Bonamino (2002).

No entanto, apesar das ressalvas que possam ser feitas a essas avaliações, elas nos dão pistas do que pode ser melhorado, não apenas para o aluno sair-se bem no exame, como, sobretudo, para poder utilizar a leitura, a fala e a escrita para se situar no mundo, para lutar por direitos, para usufruir bens culturais, para prosseguir com os estudos, para interferir nos rumos polí- ticos do país, para se inserir no mercado de trabalho, enfim, para ser cidadão.

Os resultados dos exames apontam:

- pouca familiaridade com a diversidade de gêneros discursivos;

- falta de hábito de voltar ao texto para responder a questões referentes a ele - em geral, os estudantes respondem com base no senso comum, considerando apenas as alternativas colocadas, sem relacionálas ao texto;

- dificuldade para:

1. inferir o significado de termos desconhecidos, apoiando-se no contexto;

2. localizar informações e fazer inferências a partir de gráficos;

3. integrar informações advindas de um texto verbal contínuo e de um gráfico;

4. perceber contradições no texto;

5. relacionar causa e conseqüência em textos mais longos.

Essas avaliações reafirmam o papel fundamental da escola na formação do leitor, pois os níveis mais altos são atingidos somente por aqueles que completaram as oito séries do ensino fundamental. No entanto, o aumento do nível de letramento não tem acompanhado o aumento de escolaridade.

A escolaridade da população brasileira vem aumentando significativamente. Os dados do Instituto Brasileiro de Geografia e Estatística - IBGE mostram, por exemplo, que a parcela de pessoas de 15 a 64 anos com apenas quatro anos de estudo caiu de $37,9 \%$ para $33,6 \%$, entre 2002 e 2005 , enquanto que a proporção daqueles que completaram o ensino médio ou superior subiu de $35,5 \%$ para $40,8 \%$, no mesmo período. No entanto, 0 desempenho dos brasileiros entre 15 e 64 anos mostra uma tendência de melhora em letramento em ritmo inferior ao da própria escolarização (Boletim INAF, 2007).

Os primeiros resultados da pesquisa Estudo Longitudinal da Geração Escolar - Projeto GERES, publicados em 2006 , indicam que as crianças realizam pouco progresso após a alfabetização inicial (http://www1.folha.uol.com. br/folha/educacao/ult305u18519.shtml, 03.04.2006). E os resultados do SAEB mostram que há um aumento da proficiência em leitura ao longo da escolaridade, mas, da $4^{\underline{a}}$ para a $8^{\underline{a}}$ série, esse aumento é modesto.

Esses dados não diminuem a importância da escolarização, mas indicam que a atuação da escola precisa 


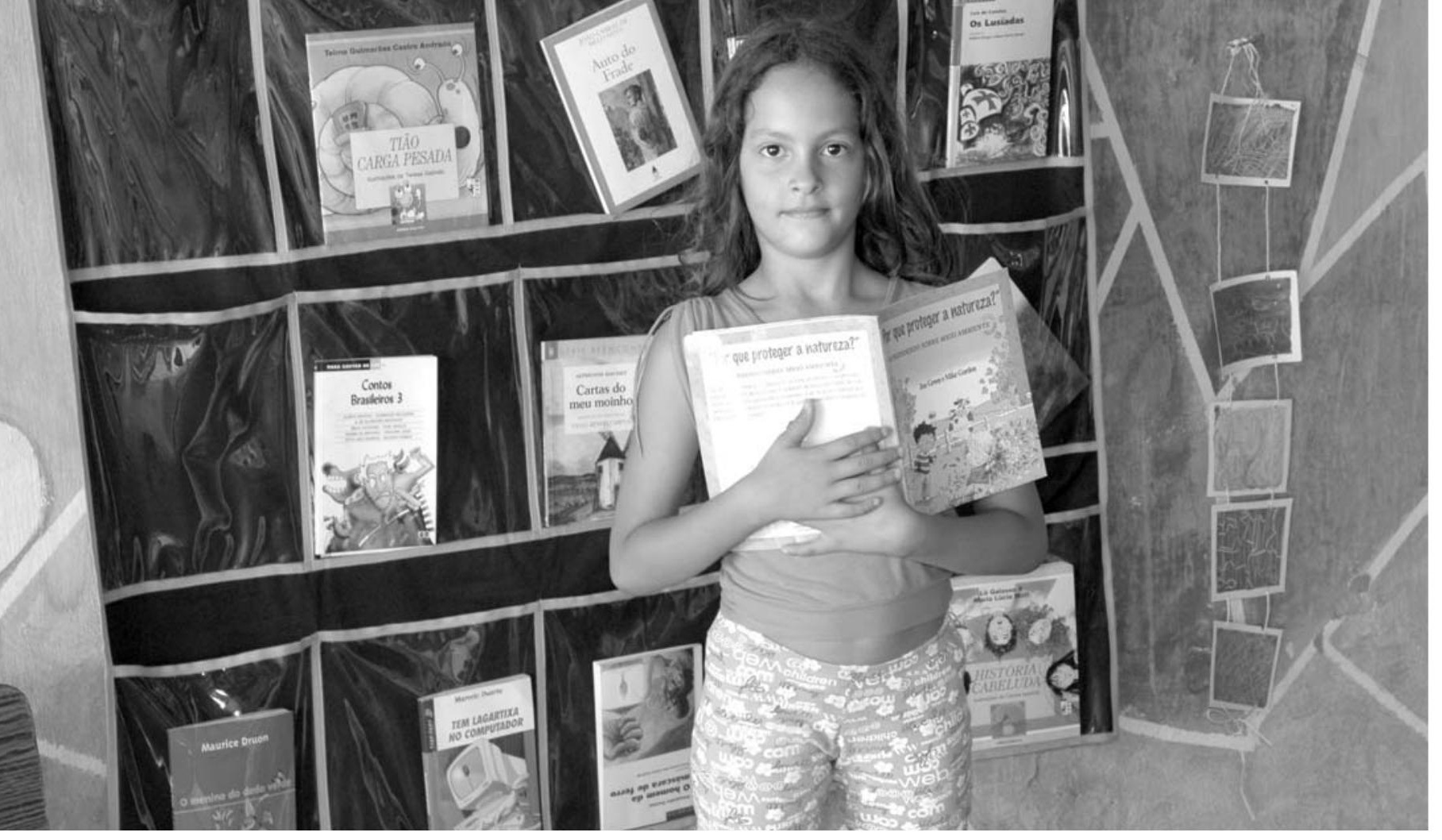

ser melhorada e que um trabalho bem planejado e consistente, com leitura e produção de textos, deve ser desenvolvido. E esse trabalho será mais efetivo se a escola interagir com as práticas culturais de seus alunos.

Evidentemente, não se trata apenas de melhorar o trabalho com a leitura e a produção de textos, como também de reprovar menos, de combater a defasagem idade-série, pois, se o ensino fundamental é tão importante, é preciso garanti-lo para todos, na idade correta prevista pela legislação. E, para isso, a escola pública precisa contar com o apoio e orientação dos órgãos governamentais.

Não basta avaliar, é preciso dar condições para que os educadores aprimorem seu trabalho e unam esforços para que todos aprendam.

\section{Leitura e produção de texto em todas as áreas do ensino}

0 desenvolvimento de capacidades de leitura e produção de textos é uma tarefa de todos os componentes curriculares e não apenas de Língua Portuguesa.

Nas aulas de Língua Portuguesa, os estudantes vão entrar em contato com diversos gêneros discursivos para apreender suas características e desenvolver capacidades de leitura e produção de diferentes gêneros, que abordam os mais diversos temas, com variadas finalidades. Nesse trabalho, o ideal é sempre preservar o máximo possível a função social que a leitura e a escrita têm fora da escola.

Cabe também à área de Língua Portuguesa o traba-
Iho de análise lingüística, de modo que os alunos se apropriem desses conhecimentos e possam ler e produzir textos, em diferentes situações escolares e nãoescolares, com clareza, coesão e correção gramatical e ortográfica.

Os professores dos outros componentes curriculares utilizam a leitura e a escrita como instrumento para a aprendizagem de conteúdos de sua área. Para que aprendam os conteúdos das áreas, os alunos precisam saber explorar um texto. Por outro lado, os conteúdos das diferentes áreas - conceitos, habilidades, valores, procedimentos que elas desenvolvem - concorrem para a ampliação do letramento, tornando o sujeito mais apto a compreender diferentes gêneros discursivos e a utilizar diferentes suportes textuais.

\section{Ler e compreender}

\section{A leitura é um processo no qual o leitor realiza um tra-}

balho ativo de construção do significado do texto. Para os leitores em formação, a mediação do professor é indispensável. Assim, antes de propor a leitura de um texto escrito, ou de um conjunto de textos, é preciso que o professor verifique as dificuldades que ele apresentará para os alunos.

A leitura é feita com diferentes objetivos: por prazer, para conhecer um determinado assunto, para se atualizar, para executar uma ação etc.

Um dos primeiros cuidados é esclarecer os objetivos da leitura: por que vamos ler, o que buscamos nesse texto ou nesse suporte textual, o que vamos fazer com 
as informações que o texto traz, que conhecimentos queremos construir. É importante lembrar que, quando perdemos de vista o motivo para fazer alguma coisa, tornamos essa ação mecânica, sem sentido e não nos mobilizamos para realizá-la de fato.

Em segundo lugar, é imprescindivel verificar o que os alunos já sabem sobre o assunto e também sobre o gênero discursivo e o suporte textual - onde o texto se encontra -, pois isso irá facilitar ou dificultar a compreensão.

É importante que o professor chame a atenção dos alunos para:

- os elementos contextualizadores - o título, a fonte, a seção/capítulo de onde foram retirados, os dados sobre o autor, a época em que foi escrito etc.;

- as possíveis intenções do autor - que informação quer transmitir, a quem quer convencer, que reflexões quer provocar, quem são seus prováveis interlocutores.

É interessante fazer perguntas com o objetivo de aguçar a curiosidade e instigar a antecipação sobre o conteúdo do texto, hipóteses que podem ser validadas ou rejeitadas na leitura subseqüente.

\section{Capacidades de leitura}

\section{Antes mesmo de se ter um texto em mãos, temos que} mobilizar determinadas capacidades de leitura. Assim, é preciso ajudar nossos alunos a: localizar e acessar fontes de consulta (bibliotecas, Internet, programas de rádio e TV, museus etc.); utilizar os fichários impressos ou a Internet para localizar obras, autores, assuntos etc.; consultar índices; localizar uma matéria dentro do jornal; avaliar criticamente as fontes (saber se são confiáveis).

Há capacidades que são comuns à leitura de diversos gêneros.

Por exemplo:

- reconhecer as características do gênero;

- identificar a finalidade do texto;

- identificar a intencionalidade do autor;

- reconhecer os efeitos de sentido - a partir de recursos gráficos, sonoros, estilísticos, semânticos, morfossintáticos etc.;

- localizar as informações explícitas;

- inferir o sentido de uma palavra pelo contexto;

- fazer as inferências globais;

- identificar os temas ou as idéias centrais;
- estabelecer relações entre as partes de um texto;

- relacionar o texto com conhecimentos do cotidiano ou especializado;

- avaliar criticamente um texto.

Outras capacidades são mais específicas a um determinado gênero.

Por exemplo:

- identificar o conflito gerador do enredo - romance, novela, crônica, contos de fadas etc.;

- distinguir o que é definição e o que é exemplo textos didáticos, verbetes, artigos científicos, teses acadêmicas etc.;

- reconhecer as posições distintas sobre um mesmo tema - artigos de opinião, debate, editorial, teses acadêmicas etc.;

- distinguir fato de opinião - reportagem, artigos de opinião, teses etc.;

- estabelecer relação entre a tese e o argumento editorial, teses acadêmicas, debate etc.;

- identificar a ordem seqüencial de procedimentos experimentos, regras de jogo, instruções de montagem, receitas culinárias etc.

É importante também ter em mente que uma mesma capacidade pode ser exercida de forma diferente, conforme o gênero. Por exemplo, é diferente localizar a informação num texto literário e num gráfico. As relações que podem ser estabelecidas entre texto verbal e imagem são diferentes para a primeira página de um jornal e numa página do livro de Ciências. E há novas necessidades surgindo, por exemplo, a capacidade de lidar com o hipertexto.

\section{E quanto à produção de textos?}

\section{No que se refere à produção de textos, é importante} que os professores das diversas áreas pensem em atividades em que a fala e a escrita tenham finalidade social, por exemplo: comunicar algo, registrar, divulgar, informar, expor, alertar, agradar, relatar, convencer, emocionar, divertir etc.

Quando falamos em produção, referimo-nos não somente aos textos escritos, como também aos orais.

0 principal objetivo de se ensinar gêneros orais na escola é desenvolver capacidades de uso social da fala, tanto nas práticas mais informais, isto é, aquelas da vida privada cotidiana - conversa, relato de experiência vivida, comentário - quanto nas mais formais, aquelas 
que ocorrem na esfera pública de comunicação - discussão em grupo, assembléia, seminário, debate. 0 trabalho com a produção oral de textos, muitas vezes esquecido pela escola, desenvolve importantes capacidades de participação social.

Para produzir textos em diferentes gêneros, é preciso conhecê-los; assim, é necessário que essa diversidade seja utilizada e trabalhada nas aulas das diferentes disciplinas do currículo. A produção de texto requer planejamento.

Esse planejamento implica tomada de decisões, como:

- qual é o melhor gênero para o objetivo que se tem: emocionar, divertir, informar, convencer, instruir, expor, comunicar-se a distância etc;

- quais são as características desse gênero: o que pode e o que não pode ser dito;

- como se estrutura, que recursos lingüísticos podem ser utilizados;

- a quem o texto se destina: onde vai circular.

Além disso, é imprescindível atentar para o que já sabemos e para o que precisamos pesquisar sobre o assunto que será tratado no texto, pois não basta saber como dizer, é indispensável também ter algo para dizer.

E não basta produzir textos. É preciso que eles sejam aperfeiçoados, tanto no que se refere ao conteúdo da área, quanto aos aspectos relacionados à situação de produção, às características do gênero e à correção gramatical - e ortográfica, no caso do texto escrito. Ainda que ensinar gramática de modo sistemático seja tarefa da área de Língua Portuguesa, ajudar o aluno a revisar o texto e a corrigir as inadequações é tarefa de todos os professores. Não se pode esperar que os estudantes construam sozinhos esses conhecimentos.

\section{Como fazer?}

\section{Como desenvolver todas essas capacidades é o desa-} fio que se coloca a todos os professores. Quando pensamos em leitura nas diferentes áreas do currículo escolar, sabemos que essa leitura tem, em geral, finalidade de estudo: ler para aprender. Isso não significa que, nas aulas desses componentes curriculares, devam circular somente textos escolares ou de divulgação científica.

0 ideal é desenvolver a unidade de estudo lançando mão de diferentes gêneros: artigos de jornal, artigos

\section{O principal objetivo de}

se ensinar gêneros orais

na escola é desenvolver

capacidades de uso social

da fala, tanto nas práticas

mais informais, isto é, aquelas da vida privada

cotidiana - conversa, relato

de experiência vivida, comentário - quanto nas

mais formais, aquelas que

ocorrem na esfera pública

de comunicação - discussão

em grupo, assembléia, seminário, debate.

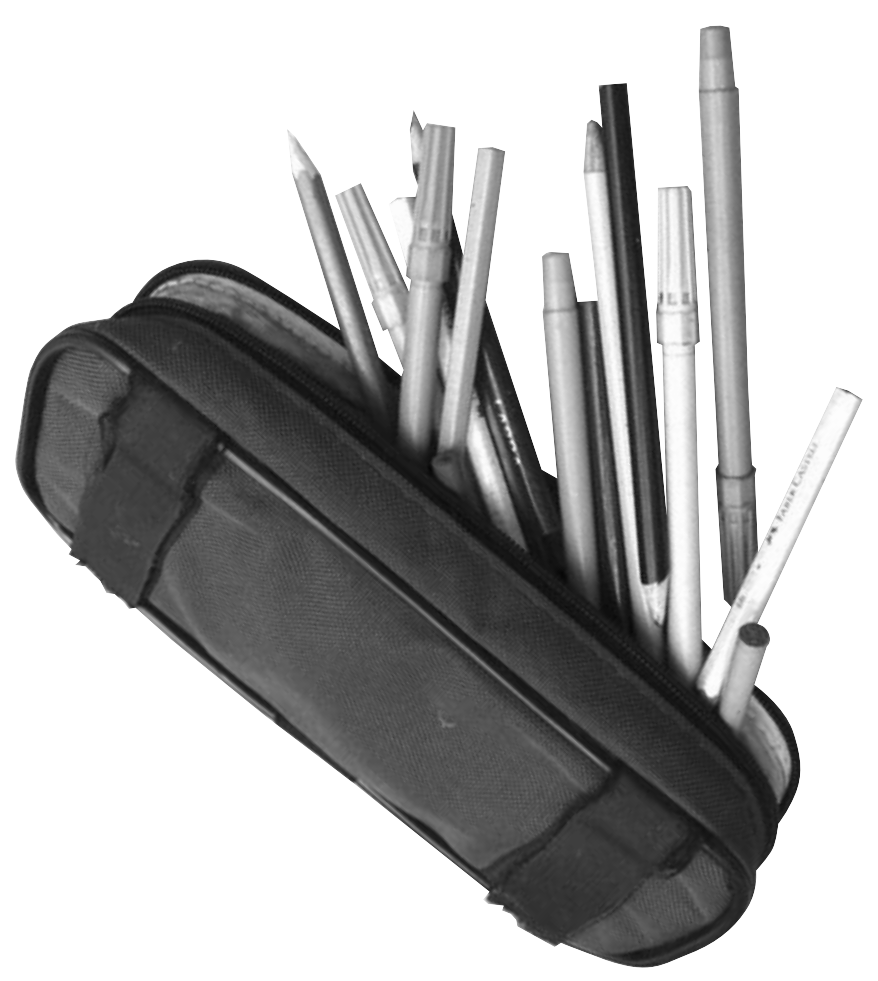


científicos, ensaios, textos didáticos, poemas, história em quadrinhos, charges, gráficos, composições musicais, crônicas, romances, fotos, memórias, depoimentos, entrevistas, textos de humor, filmes etc. Em geral, esta forma já tem sido uma prática dos professores e está muito presente nos livros didáticos.

A questão é como fazer uma adequada exploração desses diferentes textos e relacioná-los. Muitas vezes, a diversidade de textos está presente, mas todos os gêneros são trabalhados da mesma forma e se pressupõe que o aluno consiga, sozinho, fazer as relações e reflexões sobre eles, sem a mediação do professor.

No que se refere à produção de texto, em geral, as propostas são genéricas, não há explicitação do gênero em que o texto deva ser produzido, nem orientações para produzi-lo, aperfeiçoá-lo e divulgá-lo.

Como ponto de partida, há algumas perguntas que todos os professores precisam se fazer:

- Em que situações a leitura e a produção são propostas nas aulas?

- Há uma finalidade que justifica essa leitura e essa produção ou são meros exercícios escolares?

- Os alunos são esclarecidos a respeito da finalidade da atividade de leitura ou de produção de um texto?

- O que o professor espera que os alunos aprendam na sua área?

- Que gêneros são mais adequados para cada conteúdo, tendo em vista essas aprendizagens?

- O professor utiliza uma diversidade de fontes de consulta e de suportes textuais?

- Apresenta diferentes gêneros, extraídos de diferentes fontes e suportes, para abordar um mesmo tema ou para desenvolver um mesmo conceito, por exemplo: uma ilustração, um texto do livro didático, um gráfico, uma reportagem ou artigo de jornal?

- Incentiva e ajuda os alunos a comparar esses diferentes textos e a elaborar conclusões sobre o assunto, a concordar ou discordar, a se posicionar criticamente?

- Incentiva os alunos a ler, a enfrentar as dificuldades de um texto mais longo e mais complexo?

- Diante de textos mais complexos, ajuda-os a identificar idéias, teses, argumentos; a inferir dados que não estão explícitos; a inferir o significado de termos desconhecidos; a relacioná-los com outros textos lidos ou com experiências de vida?

- Planeja situações em que os alunos possam demonstrar suas aprendizagens e divulgar suas produções para outras pessoas e não apenas para o professor e os colegas de classe?

Cada área do conhecimento tem sua parte na formação do leitor e do autor de textos orais e escritos. Assim, é o trabalho conjunto dos educadores que irá garantir a ampliação do acesso das crianças e jovens ao mundo letrado.

\section{Referências e sugestões de leitura}

BAKHTIN, Mikhail (V. N. Volochinov). Marxismo e filosofia da linguagem. Trad. Michel Lahud e Yara Frateschi Vieira. São Paulo: Hucitec, 1990.

BONAMINO, A.; COSCARELLI, C.; FRANCO, C. Avaliação e letramento: concepções de aluno letrado subjacentes ao SAEB e ao PISA. Educação e Sociedade: Revista de Ciência da Educação, Centro de Estudos Educação e Sociedade, v. 23, n. 81 (Dossiê Letramento). São Paulo; Campinas: Cortez; CEDES, 2002.

BRASIL. Ministério da Educação. Lei de diretrizes e bases da Educação. Brasília: MEC, 1996.

. Secretaria de Educação Fundamental. Parâmetros curriculares nacionais: terceiro e quarto ciclos do ensino fundamental - Língua Portuguesa. Secretaria de Educação Fundamental. Brasília: MEC/SEF, 1998.

CENPEC. Estudar pra valer! Material de apoio ao Projeto Estudar pra Valer! São Paulo: 2005.

COSTA, Sergio Roberto. Interação e letramento escolar: uma (re)leitura à luz vygotskiana e bakhtiniana. Juiz de Fora; São Paulo: UFJF; Musa Editora, 2000.

DIONÍSIO, A. P., MACHADO, A. R., BEZERRA, M. A. (Org.). Gêneros textuais \& ensino. Rio de Janeiro: Lucerna, 2002.

KLEIMAN, Ângela. Oficina de leitura: teoria e prática. Campinas: Pontes, 2001.

. Texto e leitor: aspectos cognitivos da leitura. Campinas: Pontes, 1989.

(Org.). Os significados do letramento: uma nova perspectiva sobre a prática social da escrita. Campinas: Mercado de Letras, 1995.

; MORAES, Silvia E. Leitura e Interdisciplinaridade: tecendo redes nos projetos da escola. Campinas: Mercado das Letras, 1999.

LERNER, DELIA. Ler, escrever na escola: o real, o possível e o necessário. Porto Alegre: Artmed, 2002

MAYRINKI-SABINSON, M. L.T. O papel do interlocutor. In: ABAURRE, M. B. Cenas de aquisição da escrita. Campinas: ALB - Mercado das Letras, 1997.

PARANÁ. Secretaria de Estado da Educação. Ensinar e Aprender - material produzido pelo CENPEC para o Projeto Correção de Fluxo. Secretaria de Estado da Educação do Paraná, 1997.

RIBEIRO, Vera Masagão (Org.). Letramento no Brasil: reflexões a partir do INAF 2001. São Paulo: Global, 2003.

ROJO, Roxane. (Org.). A prática de linguagem na sala de aula: praticando os PCNs. São Paulo; Campinas: EDUC; Mercado das letras, 2000.

ROJO, Roxane; BATISTA, Antonio Augusto Gomes (Org.). Livro didático de Língua Portuguesa, letramento e cultura da escrita. Campinas: Mercado das Letras, 2003.

SCHENEWLY, B.; DOLZ, Joaquim et. al. Gêneros orais e escritos na escola. Campinas: Mercado das letras, 2004.

SOARES, M. Letramento: um tema em três gêneros. Belo Horizonte: Autêntica, 1998.

SOARES, Magda. Linguagem e escola: uma perspectiva social. São Paulo: Ática, 1985.

SOLÉ, Isabel. Estratégias de leitura. Porto Alegre: Artmed, 1998.

TFOUNI, Leda Verdiani. Letramento e alfabetização. São Paulo: Cortez, 2002. 


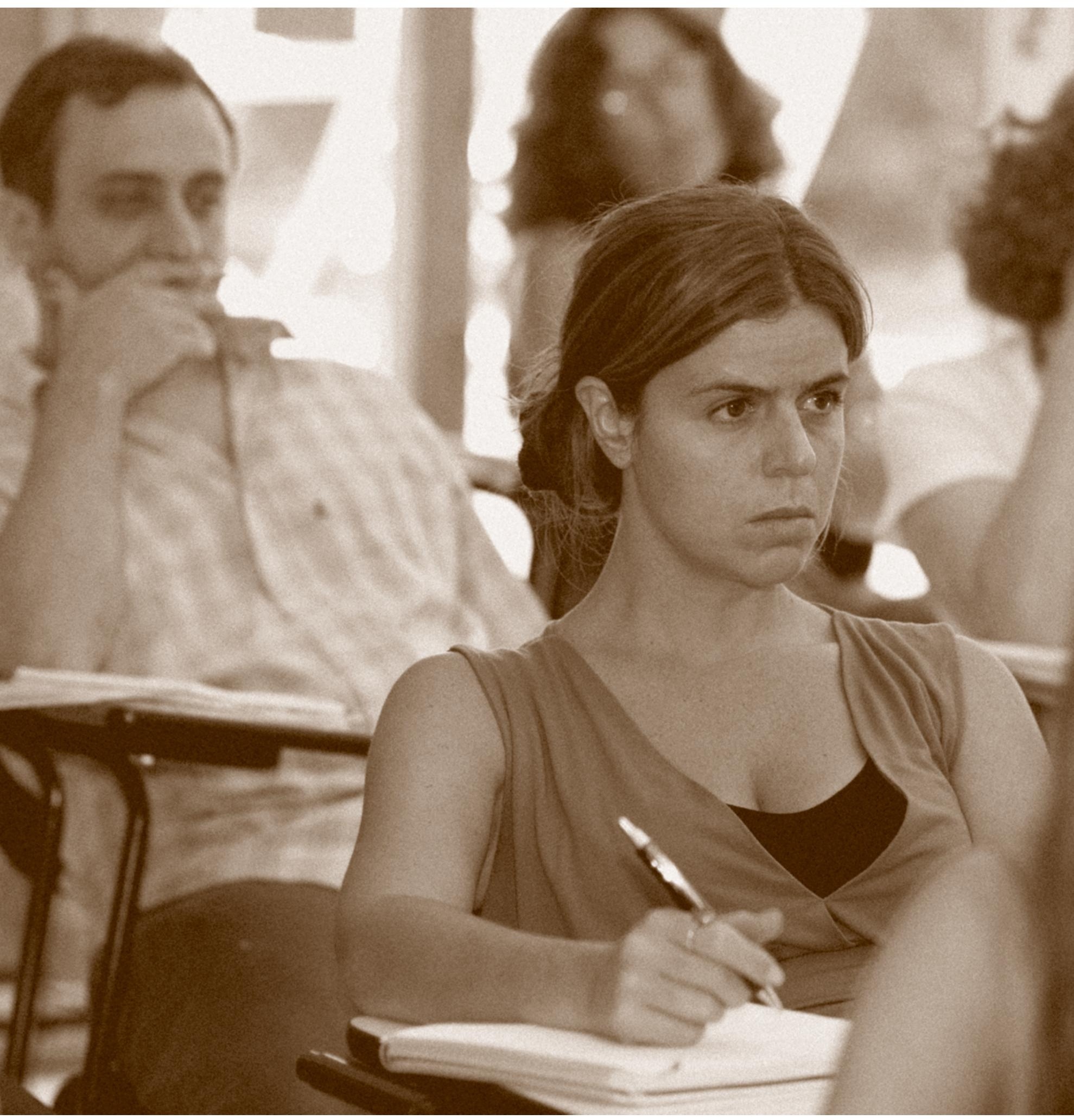

94 CADERNOS CENPEC 2007 п.3 